\title{
Do risk factors differ between explained sudden unexpected death in infancy and sudden infant death syndrome?
}

\author{
M Vennemann, T Bajanowski, T Butterfaß-Bahloul, C Sauerland, G Jorch, B Brinkmann, E A Mitchell
}

Arch Dis Child 2007;92:133-136. doi: 10.1136/adc.2006.101337

See end of article for authors' affiliations

Correspondence to Dr Mechtild Vennemann, Institute of Legal Medicine, University of Münster, Münster 48149, Germany; mechtild.vennemann @ukmuenster.de

Accepted 21 August 2006 Published Online First 25 August 2006

Background: In Germany, 2910 infants died in 2004; for many infants the reason was clear, especially prematurity or congenital abnormalities. However, 394 babies die every year suddenly and unexpectedly. The cause may be immediately clear, but is often not obvious.

Aims: (1) To describe the causes of explained sudden unexpected death in infancy (SUDI) and (2) to compare risk factors for sudden infant death syndrome (SIDS) and explained SUDI.

Methods: A 3-year population-based case-control study in Germany, 1998-2001.

Results: 455 deaths, of which 51 (11.2\%) were explained. Most of these deaths were due to respiratory or generalised infections. The risk factors for SIDS and explained SUDI were remarkably similar except for sleep position and breast feeding. Prone sleeping position is a major risk factor for SIDS (adjusted odds ratio (OR) 7.16, 95\% confidence interval (CI) 3.85 to 13.31) but not for explained SUDI (adjusted OR 1.71, 95\% Cl 0.25 to 11.57). Not being breast fed in the first 2 weeks of life is a risk factor for SIDS (adjusted OR 2.37, $95 \% \mathrm{Cl} 1.46$ to 3.84) but not for explained SUDI (adjusted OR 0.39, 95\% Cl 0.08 to 1.83).

Conclusions: Prone sleeping position is a unique risk factor for SIDS. Socioeconomic disadvantage and maternal smoking are risk factors for both SIDS and explained SUDI, and provide an opportunity for targeted intervention.

n

Germany, 2910 infants died in 2004. For some deaths the cause was obvious, such as extreme prematurity or congenital abnormalities. However, 394 infants died suddenly and unexpectedly (International classification of diseases-10th revision categories R95 and R98) in 2004. Sudden and unexpected death in infancy (SUDI) is not a diagnosis, but as its name suggests describes such deaths. SUDI cases that remain unexplained after a thorough investigation, including performance of a complete autopsy and review of the circumstances of death and clinical history, are classified as sudden infant death syndrome (SIDS). ${ }^{1}$ The proportion of SIDS varies among those presenting as SUDI. Since the "Back to Sleep" campaign, there has been a dramatic reduction in SIDS, and to a lesser extent in explained cases. Further, deaths are now labelled as "unascertained sudden infant death" because of uncertainty of the cause of death or lack of investigation.

SIDS remains the leading cause of death in the first year of life in Germany, with 323 deaths and an incidence of 0.46 per 1000 live births in $2004 .^{2}$ Since the early 1990s, the risk factors for SIDS have been examined in several well-designed casecontrol studies. ${ }^{3-6}$ The most important modifiable factors are prone and side sleeping positions, maternal smoking during pregnancy, cosleeping with the baby on the same surface, lack of breast feeding and not using a pacifier.

By contrast, risk factors for explained SUDI have rarely been reported. We conducted a case-control study on SIDS between 1998 and 2001 in Germany (German study on sudden infant death (GeSID). In this study all sudden unexpected infant deaths were examined. The specific aims of this report were (1) to describe the causes of explained SUDI in this population and (2) to compare risk factors for SIDS and explained SUDI.

\section{METHODS}

A population-based case-control study on SIDS was conducted in Germany. Between November 1998 and October 2001, 18 centres in 11 states reported cases of sudden and unexpected death in infants to the study centre in Münster. Details on case recruitment have been reported previously. ${ }^{78}$ Cases in which non-accidental injuries were suspected either during the external examination or during the autopsy were excluded from the GeSID study. All cases were subjected to an autopsy according to a standardised autopsy protocol, including histology, microbiology, virology and neuropathology examinations. Parents of such infants were interviewed at their home with a standardised questionnaire. Once all the information on one case was gathered in the study centre, a multidisciplinary panel met to define whether it was a case of SIDS or explained SUDI. The panel consisted of a forensic pathologist, a histologist, a paediatrician, a microbiologist and an epidemiologist. Cases were categorised into four groups: category 1, no signs of disease; category 2, little disease; category 3, more severe findings not sufficient as the cause of death; category 4 , a definite cause of death found.

For each case of sudden and unexpected death, three control children were recruited with the help of a registry office as described previously. The controls were matched by age, sex, sleep time and region. The controls were selected and parents were interviewed before the cause of death of the index case was established.

The socioeconomic status was defined by using a modified Scheuch index, using current income, education of the parents and their current working position. ${ }^{9}$ Cosleeping was defined as sleeping with an adult on the same surface when the child was found dead, and extra heating was classified as a hot water bottle or another heating device in the bed with the infant at the time of death or the infant's cot $<1.5 \mathrm{~m}$ from an activated heater.

All data were entered on to a database and analysed with SAS V.8.02. The age between the two groups was compared using the Wilcoxon Mann-Whitney $U$ test. The comparison of

Abbreviations: CESDI, Confidential Inquiry into Stillbirths and Deaths in Infancy; GeSID, German study on sudden infant death; SIDS, sudden infant death syndrome; SUDI, sudden unexpected death in infancy 


\begin{tabular}{ll}
$\begin{array}{l}\text { Table } 1 \text { Causes of explained sudden unexpected } \\
\text { death in infancy }\end{array}$ \\
\hline Cause of death & $\mathrm{n}(\%)$ \\
\hline Severe bronchopneumonia & $18(35)$ \\
Generalised infection & $23(45)$ \\
Vitium cordis & $4(8)$ \\
Aspiration in combination with & $2(4)$ \\
generalised infection & $1(2)$ \\
Omphalocele & $1(2)$ \\
MCAD & $1(2)$ \\
Severe meningoencephalitis & $1(2)$ \\
Dehydration & \\
\hline MCAD, medium-chain acyl-CoA dehydrogenase deficiency.
\end{tabular}

SIDS with explained SUDI was performed using logistic regression. Univariate and multivariate analyses with the cases and their matched controls were carried out using conditional logistic regression.

\section{RESULTS}

During the 3-year study period, 455 infants died within the study area, and met the inclusion criteria and could be recruited into the study. Of the 455 deaths, 33 (7.3\%) were assigned to category l, with no pathological findings at death, 278 (61.1\%) to category 2 , with minor pathological findings, 93 (20.4\%) to category 3, with more severe pathological findings but not sufficient to explain the death, and $51(11.2 \%)$ to category 4 , an explained cause of death. Table 1 shows the causes of these deaths.

The percentage of boys in the SIDS group was $60.1 \%$ and for explained SUDI was $49.0 \%$ (not significant). Figure 1 shows the age distribution for SIDS and explained SUDI cases. This difference was also not significant. Figure 2 shows the seasonal distribution for SIDS and explained SUDI cases. This difference was not significant $(\mathrm{p}=0.08)$.

The parents of $373(82.0 \%)$ of the infants were interviewed. The proportion interviewed did not vary by category $\left(\chi^{2}=2.65\right.$, $\mathrm{df}=3, \mathrm{p}=0.45)$. Overall, parents in $333(82.4 \%)$ of the SIDS cases and $40(78.4 \%)$ in the explained SUDI cases were interviewed.

The SIDS cases in which the parents were interviewed were compared with the explained SUDI cases in which the parents were interviewed (table 2). In the univariate comparison, prone sleeping position and lack of breast feeding in the first 2 weeks of life differed between SIDS and explained SUDI cases. In the multivariate analysis, only prone sleeping position differed between SIDS and explained SUDI cases; breast feeding was close to significance $(\mathrm{p}=0.069)$.

Risk factors for SIDS and explained SUDI were examined separately. As most risk factors did not differ between SIDS and explained SUDI, table 3 shows only sleep position and breast feeding. Prone sleeping position is a major risk factor for SIDS

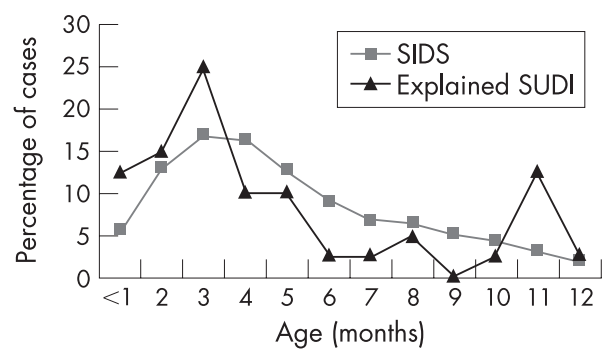

Figure 1 Age distribution of infants with sudden infant death syndrome (SIDS) and explained sudden unexpected death in infancy (SUDI).

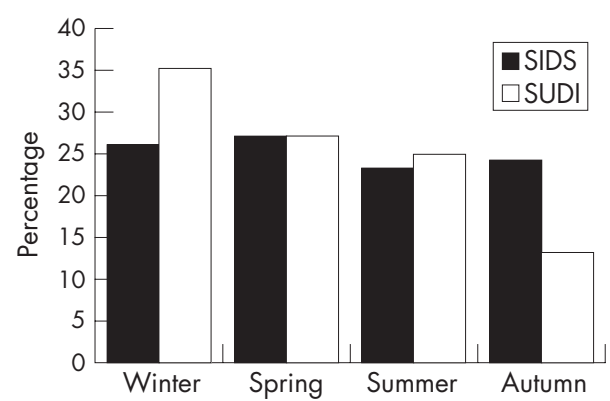

Figure 2 Distribution by season of death for sudden infant death syndrome (SIDS) and explained sudden unexpected death in infancy (SUDI).

(adjusted odds ratio (OR) 7.16, 95\% confidence interval (CI) 3.85 to 13.31) but not for explained SUDI (adjusted OR 1.71, $95 \%$ CI 0.25 to 11.57 ). Not being breast fed in the first 2 weeks of life is a risk factor for SIDS (adjusted OR 2.37, 95\% CI 1.46 to 3.84 ) but not for explained SUDI (adjusted OR 0.39, 95\% CI 0.08 to 1.83 ).

\section{DISCUSSION}

In our study, we recruited all sudden and unexpected infant deaths in the study area if they fitted the inclusion criteria (mainly aged 7-365 days, with no pre-existing life-threatening disease). Cases of clearly accidental or non-accidental injury were also excluded. Controls were enrolled for each case. Only after all the information was gathered on a case and discussed by the expert panel was the decision made whether it was a case of SIDS or an explained SUDI. In our study, all but one of the SIDS cases and all the explained SUDI cases have three matched controls. This makes our study one of the few where risk factors for SIDS and explained SUDI can be examined. To our knowledge, the only other case-control study that did this was the full Confidential Inquiry into Stillbirths and Deaths in Infancy (CESDI) study. ${ }^{10}{ }^{11}$

In our GeSID study, the same panel of experts discussed the cases over the entire study period. We found that $11 \%$ of cases had a definite cause of death identified. In an earlier study in Germany conducted between 1990 and 1994 (Westfalian Cot Death study), of 237 cases of sudden unexpected infant deaths, $36(15 \%)$ were explained. The CESDI study found $20 \%$ of explained deaths within their group of SUDI cases. The CESDI study included non-accidental injuries in the explained SUDI group, although we excluded them after the autopsy or when the state prosecutor did not close the case. In our study, such deaths account for an additional $5.8 \%$ of deaths. Thus the percentage of explained deaths is similar to that seen in the above-mentioned German study and in the CESDI study.

Despite the size of the study, the number of explained SUDI cases is relatively small, which is further reduced by some parents declining to participate in the study. This limits the power of the study, but it is sufficient to show large effects.

The strength of our study is that the information on the infants' history was gathered and the interview was conducted before it was decided whether it was a case of SIDS or an explained SUDI. The risk of recall bias between the two groups is therefore minimised.

In our study, the risk factors for both groups are strikingly similar. Many of the risk factors that are closely associated with SIDS are the same as in the explained SUDI group. Low socioeconomic status and maternal smoking during pregnancy were risk factors for both groups of infants in the univariate analysis. Although maternal smoking failed to reach statistical significance as a risk factor for explained SUDI in the 
Table 2 Differences between sudden infant death syndrome and explained sudden unexpected death in infancy

\begin{tabular}{|c|c|c|c|c|}
\hline & $\begin{array}{l}\text { SIDS } \\
\mathrm{n}(\%)\end{array}$ & $\begin{array}{l}\text { Explained SUDI } \\
\mathbf{n}(\%)\end{array}$ & $\begin{array}{l}\text { Univariate logistic } \\
\text { regression } \\
\text { OR }(95 \% \mathrm{CI})\end{array}$ & $\begin{array}{l}\text { Multivariate logistic } \\
\text { regression* } \\
\text { OR }(95 \% \mathrm{Cl})\end{array}$ \\
\hline \multicolumn{5}{|l|}{ Maternal variable } \\
\hline \multicolumn{5}{|l|}{ Maternal age (years) } \\
\hline$<25$ & $158(47.5)$ & $14(35.0)$ & $1.68(0.85$ to 3.32$)$ & $1.41(0.55$ to 3.60$)$ \\
\hline$\geqslant 25$ & $175(52.6)$ & $26(65.0)$ & 1.00 & 1.00 \\
\hline \multicolumn{5}{|l|}{ Living with partner } \\
\hline No & $68(20.4)$ & $6(15.0)$ & $1.45(0.59$ to 3.61$)$ & 1.85 (0.58 to 5.87$)$ \\
\hline Yes & $265(79.6)$ & $34(85.0)$ & 1.00 & 1.00 \\
\hline \multicolumn{5}{|l|}{ Socioeconomic status } \\
\hline Low & $164(49.6)$ & $17(42.5)$ & $1.61(0.59$ to 4.36$)$ & 0.52 (0.12 to 2.22$)$ \\
\hline Middle & $131(39.6)$ & $17(42.5)$ & $1.28(0.47$ to 3.49$)$ & $0.67(0.21$ to 2.20$)$ \\
\hline High & $36(10.9)$ & $6(15.0)$ & 1.00 & 1.00 \\
\hline \multicolumn{5}{|l|}{ Number of previous live births } \\
\hline 0 & $111(33.3)$ & $10(25.0)$ & 1.00 & 1.00 \\
\hline$\geqslant 1$ & $222(66.7)$ & $30(75.0)$ & $0.67(0.31$ to 1.41$)$ & $0.85(0.36$ to 2.00$)$ \\
\hline \multicolumn{5}{|l|}{ Maternal smoking in pregnancy } \\
\hline No & $120(36.0)$ & $16(40.0)$ & 1.00 & 1.00 \\
\hline Yes & $213(64.0)$ & $24(60.0)$ & $1.18(0.60$ to 2.31$)$ & 1.21 (0.52 to 2.85$)$ \\
\hline \multicolumn{5}{|l|}{ Infant variables } \\
\hline \multicolumn{5}{|l|}{ Birth weight (g) } \\
\hline$<2500$ & $59(17.8)$ & $4(10.0)$ & $1.95(0.67$ to 5.69$)$ & $1.39(0.44$ to 4.39$)$ \\
\hline$\geqslant 2500$ & $272(82.2)$ & $36(90.0)$ & 1.00 & 1.00 \\
\hline \multicolumn{5}{|l|}{ Ethnicity } \\
\hline Both parents European & $270(82.3)$ & $34(85.0)$ & 1.00 & 1.00 \\
\hline One or both parents not European & $58(17.7)$ & $6(15.0)$ & 1.22 (0.49 to 3.04$)$ & 1.22 (0.45 to 3.33$)$ \\
\hline \multicolumn{5}{|l|}{ Sleep position } \\
\hline Prone & $136(42.0)$ & $7(19.4)$ & 3.44 (1.37 to 8.61$)$ & 4.29 (1.45 to 12.77$)$ \\
\hline Side & $97(29.9)$ & $16(44.4)$ & $1.07(0.51$ to 2.25$)$ & $1.05(0.46$ to 2.36$)$ \\
\hline Supine & $91(28.1)$ & $13(36.1)$ & 1.00 & 1.00 \\
\hline \multicolumn{5}{|l|}{ Cosleeping with an adult } \\
\hline Yes & $48(14.4)$ & $9(22.5)$ & $0.58(0.26$ to 1.29$)$ & $0.73(0.30$ to 1.79$)$ \\
\hline No & $285(85.6)$ & $31(77.5)$ & 1.00 & 1.00 \\
\hline \multicolumn{5}{|l|}{ Pillow } \\
\hline Yes & $118(35.9)$ & $17(43.6)$ & $0.72(0.37$ to 1.42$)$ & $0.49(0.23$ to 1.05$)$ \\
\hline No & $211(64.1)$ & $22(56.4)$ & 1.00 & 1.00 \\
\hline \multicolumn{5}{|l|}{ Breast feeding for the first 2 weeks of life } \\
\hline Yes & $165(49.6)$ & $29(72.5)$ & 1.00 & 1.00 \\
\hline \multirow{2}{*}{\multicolumn{5}{|c|}{ Pacifier used in the last sleep }} \\
\hline & & & & \\
\hline Yes & $135(41.0)$ & $16(40.0)$ & $1.04(0.53$ to 2.04$)$ & $1.26(0.57$ to 2.77$)$ \\
\hline No & $194(59.0)$ & $24(60.0)$ & 1.00 & 1.00 \\
\hline \multicolumn{5}{|l|}{ Extra heating during last sleep } \\
\hline Yes & $53(16.1)$ & $6(15.8)$ & $1.02(0.41$ to 2.57$)$ & $0.93(0.35$ to 2.47$)$ \\
\hline No & $276(83.9)$ & $32(84.2)$ & 1.00 & 1.00 \\
\hline
\end{tabular}

Table 3 Univariate and multivariate odds ratios for sudden infant death syndrome and explained sudden unexpected death in infancy, for sleep position and breast feeding

\begin{tabular}{|c|c|c|c|c|}
\hline & \multicolumn{2}{|l|}{ SIDS } & \multicolumn{2}{|l|}{ Explained SUDI } \\
\hline & $\begin{array}{l}\text { Univariate OR } \\
(95 \% \mathrm{Cl})\end{array}$ & $\begin{array}{l}\text { Multivariate OR* } \\
(95 \% \mathrm{Cl})\end{array}$ & $\begin{array}{l}\text { Univariate OR } \\
(95 \% \mathrm{Cl})\end{array}$ & $\begin{array}{l}\text { Multivariate OR* } \\
(95 \% \mathrm{Cl})\end{array}$ \\
\hline \multicolumn{5}{|c|}{ Sleep position } \\
\hline Prone & $16.62(10.38$ to 26.61$)$ & $7.16(3.85$ to 13.31$)$ & $3.53(1.03$ to 12.12$)$ & $1.71(0.25$ to 11.57$)$ \\
\hline Side & $1.12(0.79$ to 1.58$)$ & $0.83(0.51$ to 1.34$)$ & $0.84(0.38$ to 1.85$)$ & $1.18(0.40$ to 3.51$)$ \\
\hline Supine & 1.00 & 1.00 & 1.00 & 1.00 \\
\hline \multicolumn{5}{|c|}{ Breast feeding for at least the first 2 weeks of life } \\
\hline Yes & 1.00 & 1.00 & 1.00 & 1.00 \\
\hline No & 5.36 (3.97 to 7.23$)$ & 2.37 (1.46 to 3.84$)$ & 1.98 (0.85 to 4.59$)$ & $0.39(0.08$ to 1.83$)$ \\
\hline
\end{tabular}

SIDS, sudden infant death syndrome; SUDI, sudden unexpected death in infancy.

*Adjusted for sleep position, breast feeding, maternal smoking during pregnancy, family status, socioeconomic status, maternal age at delivery, ethnicity, cosleeping, previous live births, birth weight and extra heating of the infant. 


\section{What is already known on this topic}

- Prone sleeping position is a well-known risk factor for sudden infant death syndrome (SIDS) in many countries.

- Since the "Back To Sleep" campaigns, the risk of dying is closely related to socioeconomic disadvantage.

\section{What this study adds}

- This is the first study to examine the sleep environment in cases of SIDS and explained sudden unexpected death in infancy (SUDI).

- Prone sleeping position was a major risk factor for SIDS but was not associated with an increased risk for explained SUDI.

multivariate model, maternal smoking did not differ between cases of SIDS and explained SUDI. Thus, maternal smoking should be considered to be a risk for explained SUDI. The CESDI study found similar results-namely, the parents from both groups came from an economically disadvantaged background and the mothers were more likely to smoke.

Sleep-environmental risk factors, such as bed sharing, pacifier use and thermal factors, did not differ between SIDS and explained SUDI. We might have expected cosleeping with adults to be more common in explained SUDI cases, as unwell infants would probably be taken into the parents' bed for comfort, but this was not seen. In some countries, death due to cosleeping is now more likely to be certified as mechanical asphyxia or undetermined than previously; however, such diagnostic transfer does not seem to be such an issue in Germany.

The major difference in risk factors between cases of SIDS and explained SUDI was sleep position. Prone sleeping position was a major risk factor for SIDS, but was not associated with an increased risk for explained SUDI. Thus, the increased risk of death with prone sleeping position seems to be unique for SIDS. This has not been reported previously.

The risk of dying in the first year of life in the case of explained SUDI or unexplained death (SIDS) is closely related to socioeconomic disadvantage. This group thus provides an identified group of infants and their families that paediatricians and all groups coming in close contact with young parents can target for health education. Not only should the SIDS risk factors be highlighted, but families should be educated to recognise the sick baby who needs the attention of a nurse or a doctor. Infectious death may be prevented in the future by such a strategy.

\section{Authors' affiliations}

M Vennemann, B Brinkmann, Institute for Legal Medicine, University of Münster, Münster, Germany

T Bajanowski, Institute for Legal Medicine, University of Duisburg-Essen, Duisburg-Essen, Germany

T Butterfaß-Bahloul, Coordinating Centre for Clinical Trials, University of Münster, Münster, Germany

C Saverland, Department of Medical Informatics and Biomathematics, University of Münster, Münster, Germany

G Jorch, Children's Hospital, University of Magdeburg, Magdeburg,

Germany

E A Mitchell, Department of Paediatrics, University of Auckland, Auckland, New Zealand

Competing interests: None.

\section{REFERENCES}

1 Krous HF, Beckwith JB, Byard RW, et al. Sudden infant death syndrome and unclassified sudden infant deaths: a definitional and diagnostic approach. Pediatrics 2004;114:234-8.

2 Statistisches Bundesamt. Statistisches Jahrbuch. Wiesbaden: Statistisches Bundesamt, 2004.

3 Fleming PJ, Gilbert R, Azaz Y, et al. Interaction between bedding and sleeping position in the sudden infant death syndrome: a population based case-control study. BMJ 1990;301:85-9.

4 Jorch G, Schmidt-Troschke S BT, Heinecke A, et al. Epidemiologische Risikofaktoren des plötzlichen Kindstods. Monatsschr Kinderheilkd 1994;142:137-47.

5 Mitchell EA, Taylor BJ, Ford RP, et al. Four modifiable and other major risk factors for cot death: the New Zealand Study. J Paediatr Child Health 1992;28(Suppl 1):S3-8.

6 Carpenter RG, Irgens LM, Blair PS, et al. Sudden unexplained infant death in 20 regions in Europe: case control study. Lancet 2004;363:185-91.

7 Findeisen $M$, Vennemann $M$, Brinkmann B, et al. German study on sudden infant death (GeSID): design, epidemiological and pathological profile. Int $J$ Legal Med 2004; 118:163-9

8 Vennemann MM, Findeisen M, Butterfass-Bahloul T, et al. Modifiable risk factors for SIDS in Germany: results of GeSID. Acta Paediatr 2005;94:655-60

9 Winkler J, Stolzenberg H. Der Sozialschichtindex im Bundes-Gesundheitssurvey. Gesundheitswesen 1998:61:178-83.

10 Leach CE, Blair PS, Fleming PJ, et al. Epidemiology of SIDS and explained sudden infant deaths. CESDI SUDI Research Group. Pediatrics 1999;104:e43.

11 Platt MW, Blair PS, Fleming PJ, et al. A clinical comparison of SIDS and explained sudden infant deaths: how healthy and how normal? CESDI SUDI Research Group. Confidential Inquiry into Stillbirths and Deaths in Infancy Study. Arch Dis Child 2000;82:98-106. 